\title{
A completed audit to reduce hospital outpatients non-attendance rates
}

\author{
A R Gatrad
}

\begin{abstract}
An audit loop for patients failing to attend a paediatric outpatient department was completed by repeating the analysis three years after interventions were put into place. The 1995 study had shown nonattendance for clinic visits was $34 \%$, varying from $32.5 \%$ for Europeans and $50 \%$ for Asian patients. A follow up study in 1998 showed a fall to $12.04 \%$ and $13.5 \%$, respectively, with an overall rate of $12.3 \%$. The Manor Hospital NHS Trust had the lowest non-attendance rate of the 30 hospitals in the West Midlands region for the year 1996-7.

(Arch Dis Child 2000;82:59-61)
\end{abstract}

Keywords: non-attendance rate; Asian; outpatient; audit

A study ${ }^{1}$ of patients failing to attend for a booked appointment in the paediatric outpatient department (OPD) at the Manor Hospital, Walsall in 1995 showed that the overall non-attendance rate for new patients and follow up appointments was 33\% and 35\%, respectively. It was noted that Asian patients failed to attend for $50 \%$ of new appointments and $50 \%$ of follow up visits compared with $32 \%$ and $33 \%$, respectively, for European patients.

The largest group of Asians in Walsall are Muslims. In the 1995 study they had a disproportionately high non-attendance rate, particularly in the month of Ramadan (fasting), which fell squarely during February 1995, and again in May 1995 during the Hajj (pilgrimage) (fig 1). We concluded that the high Asian nonattendance rate was because most Asian children booked to attend the OPD were Muslims.

The study was repeated in 1998 when Ramadan again fell fully during January. The Hajj period was, therefore, in April.

\section{Method}

During 1996 and 1997 various interventions were put in place, including those resulting from the previous study. These were:

(1) Better communication, including the use of existing link workers for patients from all communities, but particularly Muslims from Bangladesh. Many of the latter, particularly women, only speak Sylethi and not Hindi, which is the main Asian language spoken in the UK.

(2) Outpatient clerks were given, in advance, a list of dates for the fasting month and religious festivals, including pilgrimage. Be- cause Friday is a religious day for Muslims, with prayers at around midday, appointments were no longer offered late in the mornings or early in the afternoon. When making follow up appointments, patients were specifically asked by doctors and other clinic staff whether an appointment clashed with their travel abroad or religious holidays.

(3) Midwives were made aware that Muslim mothers might stay at home for six weeks after their baby is born and, therefore, might not be able to attend outpatient appointments. Furthermore, they were told that a grieving Muslim wife may not leave her home for up to four months after her husband's death.

(4) I communicated with local mosques and advised elders to impress on the community the importance of keeping appointments, and to bring to their attention communication services in Asian languages provided by the hospital.

(5) All patients were given forms on which to fill in their correct addresses and telephone numbers before being seen by the consultant in the OPD. Appropriate changes were made on the patient management system to ensure that appointments did not go to the wrong address and that patients could be contacted by telephone if necessary.

(6) Parents were telephoned by the clinic nurse, after 17:00, 24-48 hours before their appointment.

(7) Consultants personally went through the notes of defaulters and made appropriate follow up arrangements.

(8) Better signposting in the hospital.

Once the above interventions were in place, non-attenders were studied prospectively over 12 months (January to December 1998). The data were collected manually and confirmed electronically. Children attending ear nose and throat, general surgery, orthopaedic, and dermatology OPDs were excluded. Patients were categorised as European (E), Muslim (M), Sikh $(\mathrm{S})$, and Hindu $(\mathrm{H})$, the last three groups forming the Asian group. In the analysis, nonattendance was divided by month to ascertain any seasonal variation. As in 1995, the five consultants (two European and three Asian) held 13 clinics each week between them. Waiting time for a new appointment in the OPD in 1998 was similar to that in 1995 (three to five weeks).

\section{Results}

From table 1 it can be seen that the non-attendance rate for all booked patients was 1118 of 9099 (12.3\%); for Asians it was 202 of $1496(13.5 \%)$ and for European 916 of 7603 
Table 1 Ethnic groups attending the outpatient department and those not attending

\begin{tabular}{llllll}
\hline & Muslim & Sikh & Hindu & European & Total \\
\hline Expected & 1061 & 304 & 131 & 7603 & 9099 \\
Attended & 923 & 259 & 112 & 6687 & 7981 \\
Non-attendance rates & $138(13 \%)$ & $45(15 \%)$ & $19(14.5 \%)$ & $916(12 \%)$ & $1118(12.3 \%)$ \\
\hline
\end{tabular}

(12\%). The non-attendance rate for Muslims was $13 \%$ (138 of 1061) and for non-Muslim Asians 64 of 435 (14.8\%).

There were no significant differences when $\chi^{2}$ tests were applied to $12 \times 12$ contingency tables to test for independence between ethnic origin and month of non-attendance. The following values were found: Muslim $v$ the others (Hindu, Sikh, and European), $\mathrm{p}=0.35$; Muslim $v$ non-Muslim Asians, $\mathrm{p}=0.43$; Muslim $v$ European, $p=0.38$; Asian group $v$ European, $p=0.58$. Therefore, for each test the two parameters were independent-there was no relation between ethnic origin and month of non-attendance.

\section{Discussion}

It was appropriate to repeat the study three years later because the Muslim lunar calendar is 355 days so Ramadan, the holy month of fasting, occurred in January 1998. Analysis would have been difficult had the study been repeated any earlier because Ramadan would have straddled two months in both 1996 and 1997. However, retrospective electronic analysis for the calendar year 1997 (by which time interventions were in place at the Manor Hospital) disclosed that the non-attendance rate had already improved considerably to $13.5 \%$.

A previous study of 530 families in Walsall revealed that $84 \%$ of Asian and $65 \%$ of European homes had telephones. I consider that telephoning patients as described above was probably the most important factor in the decrease in non-attendance. This conclusion is based on the fact that from January to March 1999 we did not telephone patients and this

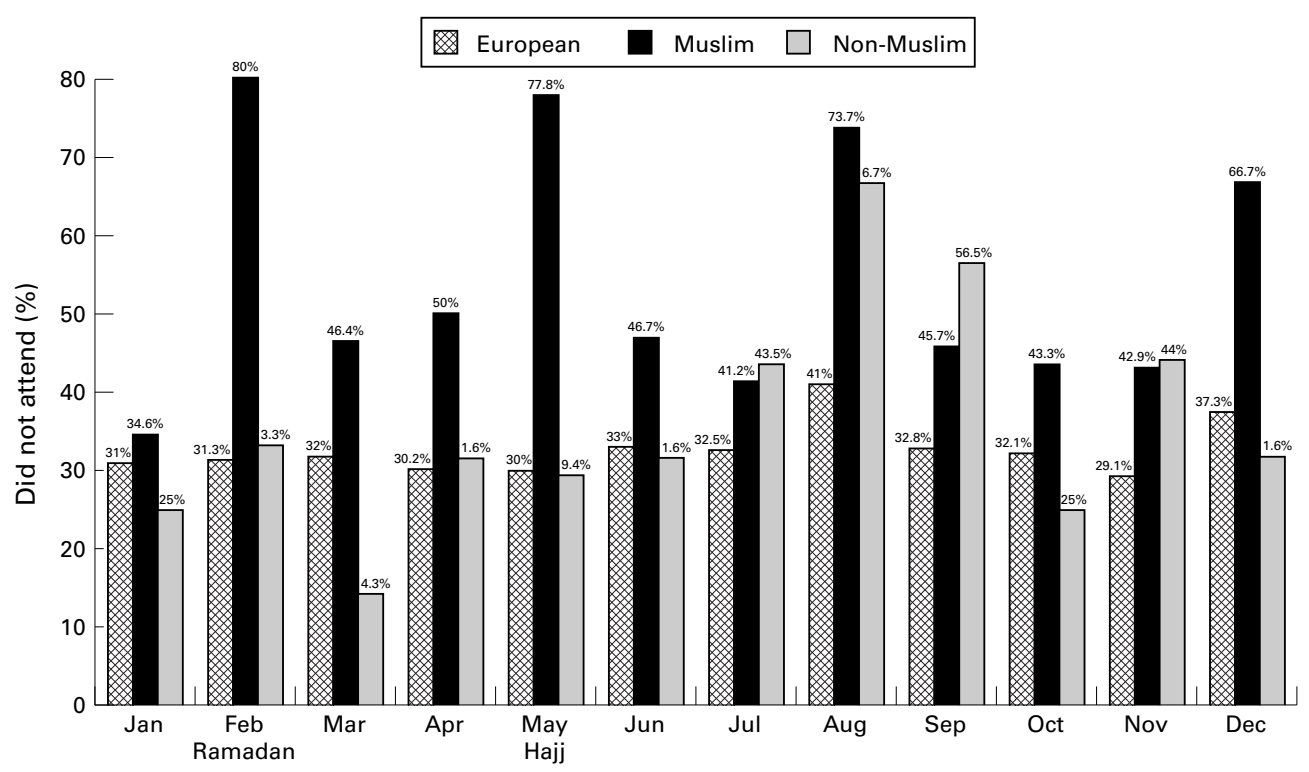

Figure 1 Monthly variation in the proportion of patients that did not attend the paediatric outpatient department, 1995.

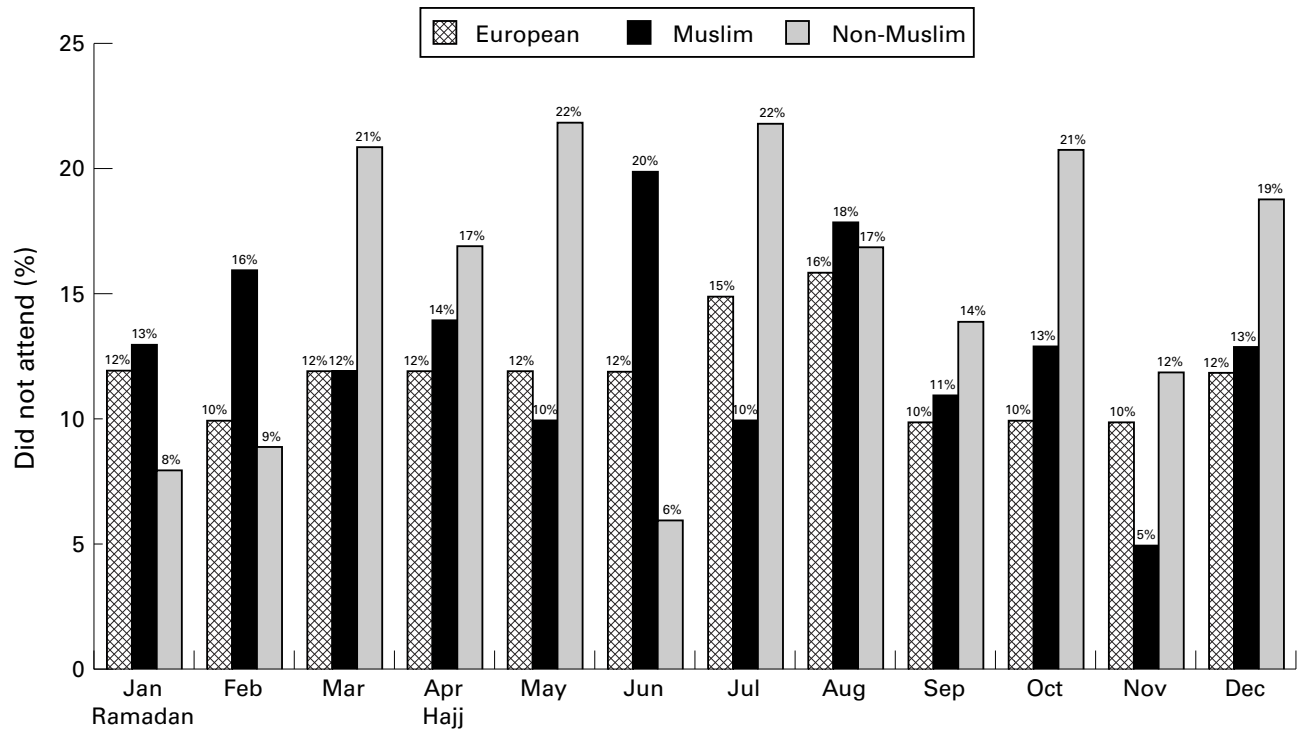

Figure 2 Monthly variation in the proportion of patients that did not attend the paediatric outpatient department, 1998. 
resulted in an average increase of the nonattendance rate to $17.5 \%$ for each month. Therefore, we have reinstated the practice of telephoning patients to remind them of their appointment and this has resulted in an improvement in the non-attendance rate. The difficulty communicating with Asian parents on the telephone was partly alleviated by the fact that most men, who have less difficulty in communicating in English than women, were at home after 17:00.

The results show clearly that the interventions were effective because the overall nonattendance rate dropped from over $50 \%$ in 1995 to less than $13 \%$ in 1998 . There was a pronounced improvement in the nonattendance rate of Muslims, which was now comparable with that of European patients (table 1). Furthermore, over the religious months of January and April 1998 there was no evidence of a disproportionate increase in nonattendance rate among Muslims (fig 2). Moreover, although Muslims are the main population among Asians in Walsall, their nonattendance rate was less than that of the non-Muslim Asian group. This might have been a result of my personal contact with the Muslim community. Because Hindu and Sikh attendance was proportionately lower in the 1995 study, their places of worship were not visited. Information about religious holidays in ethnic groups can be obtained from a multicul- tural calendar (available from Shap Working Party, c/o NSREC, 36 Causton Street, London SW1P 4AU, UK).

Our overall figure for non-attendance rates for the calendar year $1998(12.3 \%)$ is comparable with that produced by the NHS Executive $(12.99 \%)$ in the West Midlands ${ }^{3}$ for Walsall for 1996-7. Manor Hospital had the lowest number of non-attendances among 30 units in the West Midlands in 1996-7. Such a dramatic decrease will reduce the cost of nonattendance, estimated at $£ 2.4$ billion for the UK as a whole in $1995 .{ }^{4}$

We intend to continue improving the nonattendance rate still further through regular dialogue with general practitioners and the Asian community (the latter through religious centres) to ensure that the hard work by receptionists, nurses, and doctors alike continues to achieve good results.

Thanks to A Mainwaring from the information department for help with the statistics and to $S$ Perry for secretarial help.

1 Gatrad AR. Comparison of Asian and English nonattenders at a hospital out-patient department. Arch Dis Child 1997;77:423-6.

2 Gatrad AR. A study of Asian and English out-patient attendance [dissertation]. Keele University: Diploma in Health Management, 1998.

3 NHS Executive. Comparative information system. West Midlands: West Midlands Regional Office, Information Analysis Department, 1998 .

4 National Audit Office. NHS out-patient services in England and Wales. London: HMSO, 1995:5. 